\title{
A Comparative Evaluation of Shear Bond Strength of Seventh- and Eighth-Generation Self-etch Dentin Bonding Agents in Primary Teeth: An In Vitro Study
}

\author{
Ankur Mishra ${ }^{1}$, Monika Koul ${ }^{2}$, Vinod K Upadhyay ${ }^{3}$, Ahsan Abdullah ${ }^{4}$
}

\begin{abstract}
Aim: To compare the shear bond strength of seventh- and eight-generation self-etch dentin bonding agents in primary teeth using universal testing machine.

Materials and methods: Forty extracted sound human primary molars were collected and randomly divided into two groups of 20 sample each. Shear bond strength of seventh-generation bonding agent [ADPER Single Bond Universal, (group II)] and eighth-generation bonding agent [Futurabond DC, VOCO Germany, (group I)] were calculated by using Universal Testing Machine (PTC/O83/ME, INSTRON, USA) and expressed in megapascals (MPa). Recorded data were compiled and subjected to statistical analysis using Student's $t$ test.

Results: The mean shear bond strength of group I (eighth-generation dentin bonding agent) and group II (seventh-generation dentin bonding agent) ranged from 22.10 to $37.10 \mathrm{MPa}$ and 19.80 to $30.30 \mathrm{MPa}$, respectively Student's $t$ test showed significantly different and higher (8.7\%) shear bond strength in group I when compared to group II ( $p$ value $=0.017$ ).

Conclusion: Shear bond strength of eighth-generation dentin bonding agent (Futurabond DC) was better than seventh-generation dentin bonding agent (Adper Single Bond Universal).

Clinical significance: An effective bond to tooth would reduce marginal microleakage, bacterial penetration, postoperative sensitivity, possibility of pulpal inflammation, and preserve tooth structure by allowing minimal cavity preparation.

Keywords: Dentine bonding agents, Seventh- and eight-generation bonding agents, Shear bond strength, Universal testing machine.

International Journal of Clinical Pediatric Dentistry (2020): 10.5005/jp-journals-10005-1765
\end{abstract}

\section{INTRODUCTION}

Esthetic restorations of primary teeth are a challenging task for the dentist due to thin enamel, pulpal anatomy, and small size of the tooth. Restoration of primary teeth that are discolored, malformed, have multiple surface caries, or destructed due to trauma is a matter of great concern for the patient as well the parents. ${ }^{1}$ Nowadays, composite is one of the most popular and promising tooth colored restorative materials, which bonds to the tooth with the help of adhesive, i.e., bonding agents. ${ }^{2,3}$ An effective bond would reduce marginal microleakage, bacterial penetration leading to secondary caries, postoperative sensitivity, possibility of pulpal inflammation, and conserve the tooth structure by allowing minimal cavity preparation. $^{4}$

In vitro tests play a significant role in providing the necessary information regarding the effectiveness of new materials with less cost and in a short period of time, whereas clinical studies would provide information only after the use for long period. ${ }^{5-7}$ The most frequently applied laboratory parameter to evaluate the effectiveness of dentin bonding agent is shear bond strength test, ${ }^{7}$ thus implying that much of the data that are available on dental adhesion comes from the shear bond strength test. Low shear bond strength is associated with insufficient bonding and wider gaps between resin restoration and tooth. Previous studies on shear bond strength assessment of self-etching adhesive have shown inconclusive results on primary dentin. Thus, the aim of this in vitro study was to evaluate and compare the shear bond strength of seventh-and eight-generation self-etch dentine bonding agents in extracted primary teeth using universal testing machine (UTM).
${ }^{1-4}$ Department of Pedodontics and Preventive Dentistry, Career Post Graduate Institute of Dental Sciences and Hospital, Lucknow, Uttar Pradesh, India

Corresponding Author: Monika Koul, Department of Pedodontics and Preventive Dentistry, Career Post Graduate Institute of Dental Sciences and Hospital, Lucknow, Uttar Pradesh, India, Phone: +91 8005218802, e-mail: monikakoul25@gmail.com

How to cite this article: Mishra A, Koul M, Upadhyay VK, et al. A Comparative Evaluation of Shear Bond Strength of Seventh- and Eighth-generation Self-etch Dentin Bonding Agents in Primary Teeth: An In Vitro Study. Int J Clin Pediatr Dent 2020;13(3):225-229.

Source of support: Nil

Conflict of interest: None

\section{Materials and Methods}

Forty sound human primary maxillary and mandibular molars were collected which were extracted for orthodontic purpose, overretention, or physiologic resorption. Noncarious teeth, unrestored teeth, and teeth without any dental anomalies were included in the study, while carious teeth, teeth with dental anomalies, and teeth with restorations were excluded. The extracted teeth were cleaned, polished with slurry of pumice to remove plaque, pellicle, and stains, and were stored in artificial saliva (Wet Mouth, ICPA) at room temperature. Roots of all the teeth were cut from cementoenamel junction using slow speed straight handpiece equipped with diamond disk bur. The root portions were discarded, and only the crown portion was used in the study. 
The 40 samples were randomly divided into 2 groups of 20 sample each to study shear bond strength of seventh- and eightgeneration generation bonding agents (Table 1). The self-etch bonding agents, that is, eighth-generation (Futurabond DC, VOCO Germany), was categorized as group I and seventh-generation (Adper Single Bond Universal) was categorized as group II and are listed in Table 2.

\section{Measurement of Shear Bond Strength}

Prepared crown portions of the 40 teeth were embedded in a mold containing chemically cured acrylic resin having dimension of 1 (width) $\times 2 \mathrm{~cm}$ (height) (Fig. 1) The teeth were embedded such that the occlusal surfaces projected just above the acrylic resin. A deep cut was made on the central occlusal fissure of every tooth in mesiodistal direction using diamond-tapered fissured bur (TF-11 ISO 173/014 FG, Mani, Japan) under water cooling to expose the dentin (Fig. 2). The flat dentinal surface was then finished using a 1,200-grit silicon finishing paper. Each tooth was labeled with a

Table 1: Distribution of samples

\begin{tabular}{|c|c|c|c|}
\hline $\begin{array}{l}\text { Evaluation } \\
\text { of bonding } \\
\text { efficacy by }\end{array}$ & $\begin{array}{l}\text { Number of } \\
\text { sample } \\
(N=40)\end{array}$ & $\begin{array}{l}\text { Eighth-generation } \\
\text { dentin bonding } \\
\text { agent; Futurabond } \\
\text { DC (VOCO, } \\
\text { Germany) (group I) }\end{array}$ & $\begin{array}{l}\text { Seventh- } \\
\text { generation dentin } \\
\text { bonding agent; } \\
\text { ADPER Single } \\
\text { Bond Universal } \\
\text { (3M, Germany) } \\
\text { (group II) }\end{array}$ \\
\hline $\begin{array}{l}\text { Shear bond } \\
\text { strength }\end{array}$ & 40 & $n=20$ & $n=20$ \\
\hline
\end{tabular}

different number, and the teeth were randomly divided into two groups equally $(n=20)$. Samples of both the groups were dried thoroughly with uncontaminated oil and moisture-free compresed air. In group I, that is, eighth-generation bonding agent, Futurabond DC was applied, and in group II that is, seventh-generation bonding agent, Adper Single Bond Universal dentin bonding agent was applied according to manufacturer's instructions and light cured for 10 seconds (Fig. 3). Samples of both the groups were restored with light curing composite (Beautifil, Shofu) with Teflon mold of $2 \times 3 \mathrm{~mm}$ diameter on the dentinal surface and was light cured for 10 seconds. Finally, the restorations were polished with polishing disks and cups (Super-Snap, Shofu Inc., Kyoto, Japan) (Fig. 4).The filled samples were stored in $0.9 \%$ normal saline solution for 24 hours at $37^{\circ} \mathrm{C}$ before testing. The samples were placed in semi-open front hydraulic wedge grips of Instron universal testing machine (PTC/O83/ME, INSTRON, USA) and tightly locked. The machine was adjusted so that the force was applied to the base of the compositetooth interface at a crosshead speed of $1 \mathrm{~mm} /$ minute with a knifeedged rod $0.5 \mathrm{~mm}$ thick. (Fig. 5) The shear bond strength values were measured for each sample from each group. The shear bond strength values were calculated and expressed in megapascals (MPa) (Table 3). Recorded data were compiled and subjected to statistical analysis (Fig. 6).

\section{Observations and Results}

The mean shear bond strength of group I (eighth-generation dentin bonding agent) and group II (seventh-generation dentin bonding agent) ranged from 22.10 to $37.10 \mathrm{MPa}$ and 19.80 to $30.30 \mathrm{MPa}$, respectively, with mean $( \pm \mathrm{SE}) 28.72 \pm 0.78 \mathrm{MPa}$ and

Table 2: Bonding agents used in study

\begin{tabular}{|c|c|c|c|}
\hline $\begin{array}{l}\text { Generation of bonding } \\
\text { agent }\end{array}$ & Trade name & Manufacture & Composition \\
\hline $\begin{array}{l}\text { Eighth-generation } \\
\text { dentin bonding } \\
\text { agent }\end{array}$ & Futurabond DC & VOCO Germany & $\begin{array}{l}\text { Organic acids, BIS-GMA (bisphenol a glycidyl methacrylate), HEMA (2-hydroxy } \\
\text { ethyl methacrylate), TMPTMA (trimethylolpropane trimethacrylate), BHT } \\
\text { (butylhydroxytoluene), ethanol, fluorides, } \mathrm{CQ} \text { (camphorquinone; photoinitiator), } \\
\text { amine, catalysts, highly functionalized } \mathrm{SiO}_{2} \text { nano particles }(20 \mathrm{~nm})\end{array}$ \\
\hline $\begin{array}{l}\text { Seventh-generation } \\
\text { dentin bonding } \\
\text { agent }\end{array}$ & $\begin{array}{l}\text { ADPER Single } \\
\text { Bond Universal }\end{array}$ & $\begin{array}{l}\text { 3M ESPE, Neuss, } \\
\text { Germany }\end{array}$ & $\begin{array}{l}\text { MDP phosphate monomer(10-methacryloyloxydecyl dihydrogen phosphate), } \\
\text { dimethacrylate resins, HEMA (2-hydroxy ethyl methacryate), Vitrebond } \\
\text { copolymer (methacrylate functionalized polyalkenoic acid), filler, water, } \\
\text { initiators, silane }\end{array}$ \\
\hline
\end{tabular}

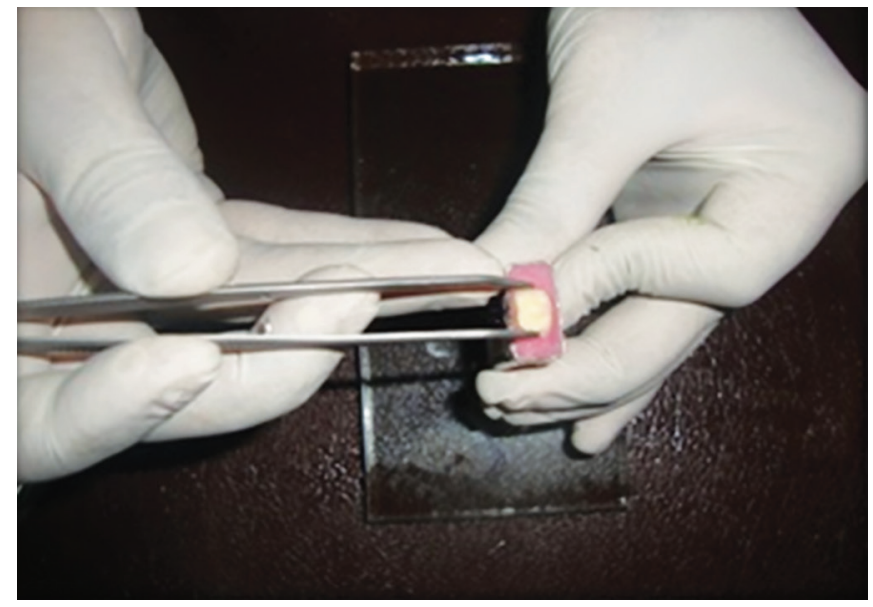

Fig. 1: Crown portion embedded in a mold containing cured acrylic resin

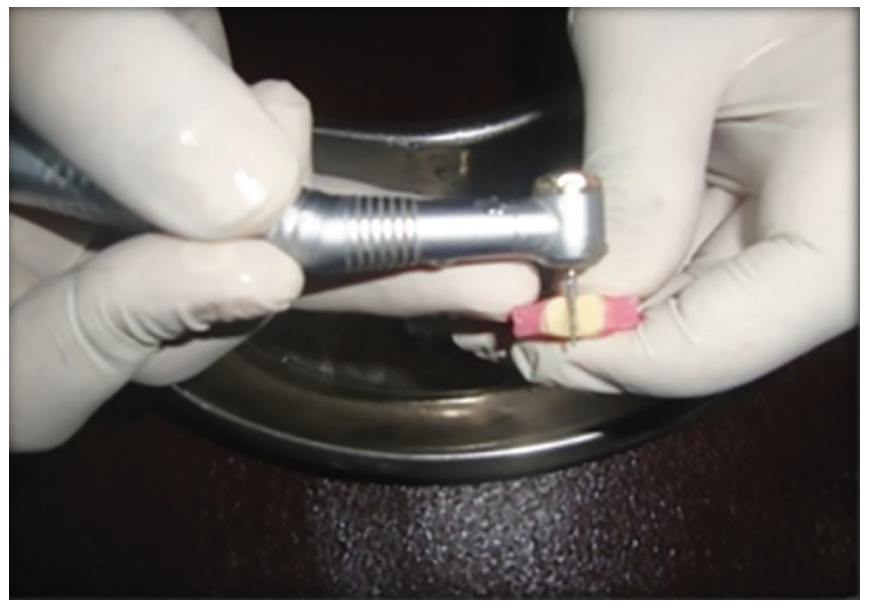

Fig. 2: Exposure of dentinal surface 

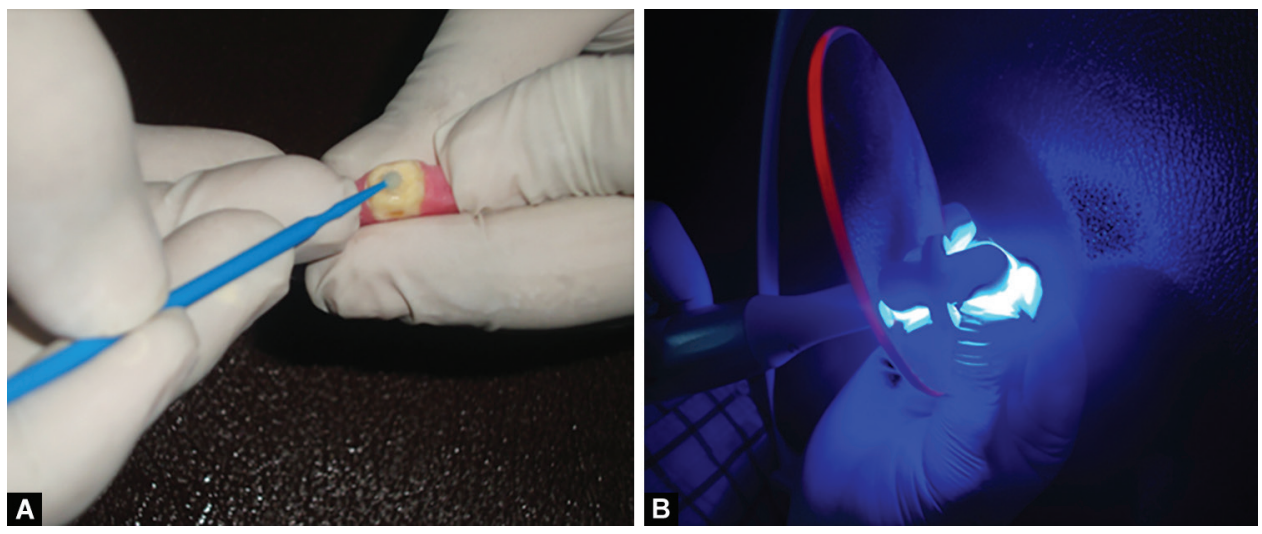

Figs $3 A$ and B: (A) Application of bonding agent; (B) Light-curing of bonding agent
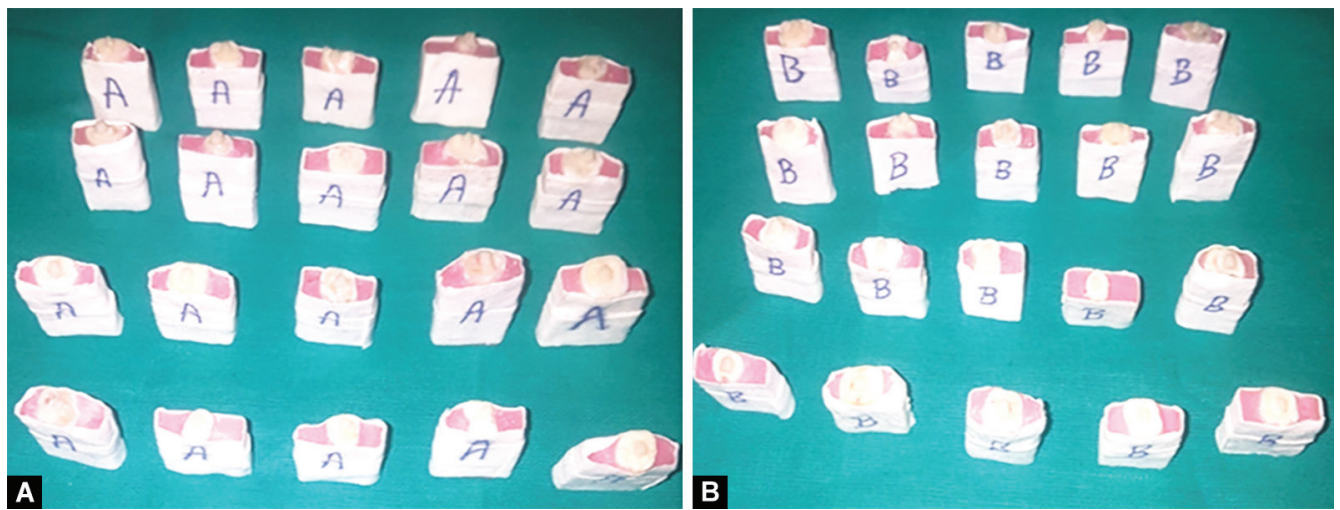

Figs $4 A$ and B: Samples after restoration

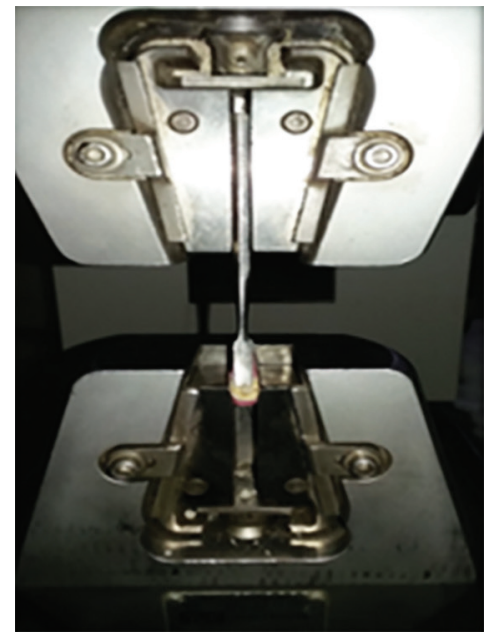

Fig. 5: Testing of sample with universal testing machine

Table 3: Shear bond strength (mean $\pm \mathrm{SE}$ ) of two groups

\begin{tabular}{lllll}
\hline $\begin{array}{l}\text { Group I } \\
\text { ( } n=20)\end{array}$ & $\begin{array}{l}\text { Group II } \\
\text { ( } n=20)\end{array}$ & $\begin{array}{l}\text { Mean diff. } \\
\text { (95\% Cl) }\end{array}$ & Tvalue & $p$ value \\
\hline $28.72 \pm 0.78$ & $26.22 \pm 0.62$ & $2.51 \pm 1.00$ & 2.50 & 0.017 \\
(22.10 to 37.10) & $(19.80$ to 30.30$)$ & $(0.48$ to 4.53$)$ & & \\
\hline
\end{tabular}

Number in parenthesis indicates the range ( $\min$ to $\max$ ); $\mathrm{Cl}$, confidence interval

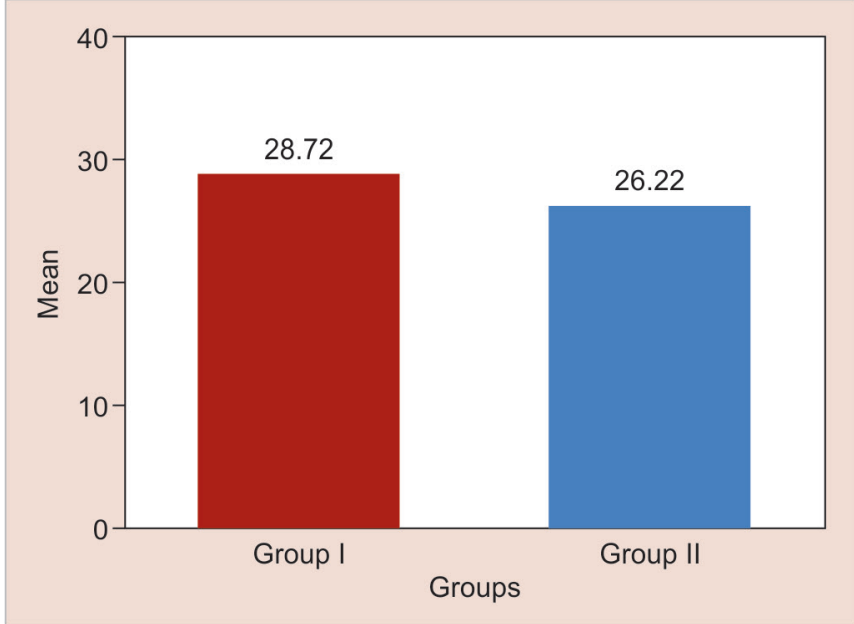

Fig. 6: Comparison of mean shear bond strength between the two groups. * $p$ value $<0.05$ when compared to group. Group I: Eighthgeneration bonding agent (Futurabond DC). Group II: Seventhgeneration bonding agent (Adper Single Bond Universal)

$26.22 \pm 0.62 \mathrm{MPa}$, respectively, and median of 28.60 and 26.65 $\mathrm{MPa}$, respectively. Student's $t$ test showed significantly different and higher (8.7\%) shear bond strength in group I when compared to group II ( $p$ value $=0.017$ ) 


\section{Discussion}

Newer adhesive systems have substantially reduced the need for extensive tooth preparation, thus allowing more conservative preparation, reduced reliance on micromechanical retention, and less removal of unsupported enamel. ${ }^{8}$ Clinically, the success of restoration depends on the stable adhesion between the resin composite and the tooth that is reliant on an ideal interaction between resin cement, adhesive system, and dental substrate. The deciduous teeth were selected for the experimental study because manufacturers of dentine bonding agent do not provide specific instructions for their use in primary teeth, although there is some difference in micromechanical and histological characteristics of primary teeth from the permanent teeth, and studies on primary teeth are scarce. ${ }^{9-11}$

Recently, the manufacturers formulated etchant, primer, and bonding agents combination in a single bottle which is commonly known as self-etch bonding agents. All the bonding agents used in this study are self-etch bonding agents, i.e., Adper Single Bond Universal (3M) which is seventh-generation dentin bonding agent and Futurabond DC (VOCO) is eighth-generation dentin bonding. Adper Single Bond Universal (3M) is a light-cure adhesive that is ideal for both direct and indirect applications. It is a one-step, one-coat application for a quick 35-second working time, i.e., application for 20 seconds, drying for 5 seconds, and then light curing for 10 seconds. ${ }^{12}$ Futurabond DC (VOCO) is a dual-curing adhesive, i.e., chemical and light cure and reinforced with nanofillers. It has an advantage of chemical curing in areas inaccessible to light curing. It has same adhesive properties as total-etch preparations without separate etching for the tooth substance. It is also a onestep, one-coat application for a quick 35-second working time, i.e., application for 20 seconds, drying for 5 seconds, and then light curing for 10 seconds. ${ }^{13}$

The present study was designed as an in vitro one because in vitro research is an important aspect of the development of newer materials and helps the clinician to understand the physical, mechanical, and biological properties of the dental materials ${ }^{6}$ Shear bond strength is the most often used laboratory parameter in measurement and evaluation of the efficacy of dentin adhesive system..$^{8,14,15}$ In our study, UTM Instron was used, which is conventionally popular for evaluating the adhesive ability of adhesive/restorative materials, ${ }^{16}$ and it was also used by Joseph et al. ${ }^{17}$ to compared bond strength of sixth- (Clearfil SE), seventh(Adper Easy One), and eighth (Futurabond DC) generation dentin bonding agents and inferred that the highest bond strength was seen in eighth-generation dentine bonding agent (34.9332 MPa) followed by sixth- and seventh-generation (32.4377 and 31.8826 $\mathrm{MPa}$, respectively) that was also seen in our study. When comparing the mean shear bond strength, eighth-generation dentin bonding agent, that is, Futurabond DC, shows highest bond strength ranging from 22.10 to $37.10 \mathrm{MPa}$ than seventh-generation dentin bonding agent, that is, Adper Single Bond Universal, that ranges from 19.80 to $30.30 \mathrm{MPa}$, respectively, with mean $( \pm \mathrm{SE})$ of $28.72 \pm 0.78 \mathrm{MPa}$ and $26.22 \pm 0.62 \mathrm{MPa}$, respectively, and was statistically just significant ( $p$ value $<0.05$ ). Shear bond strength in Futurabond DC was $8.7 \%$ higher than Adper Single Bond Universal, and these findings were in accordance with the findings of Kambel et al. ${ }^{18}$ compared in vitro tensile bond strength of sixth-generation bonding agent (Adper Se Plus; 3M ESPE), seventh-generation bonding agent (G-bond; GC Corp. Japan), and eighth-generation dentin adhesives (Futurabond DC; Voco, Germany) on 60 extracted permanent teeth. All samples were placed in saline for 24 hours, and tensile bond strength testing was done using UTM (KIC-3-050-C, Kalpak Instruments). They concluded that tensile bond strength of eighth-generation dentin bonding agent was highest (34.74431) followed by sixth-generation dentin bonding agent (32.2465) and seventh-generation (31.6734). Contrary to the result of our study, El Sayed et al. ${ }^{19}$ investigated the effect of thermocycling on the microshear bond strength of solvent-free self-etch adhesive system (Bond-1SF) and solvent containing self-etch adhesives (Futurabond DC and Adper Easy) on 60 caries-free third molars. The results showed that without thermocycling, the bond strength of Futurabond DC was less compared to Adper Easy, while Bond-1 SF solvent-free one step had the lowest mean value.

The eighth-generation dentin bonding agent (Futurabond DC) contains polyfunctional adhesive monomers (phosphoric acid modified methacrylate esters). Moreover, the eighthgeneration dentin bonding agent (Futurabond DC) contains highly functionalized $\mathrm{SiO}_{2}$ nanoparticles $(\varnothing 20 \mathrm{~nm}$ ) that facilitate cross-linking of the resin components. ${ }^{13}$ Nanofilled adhesive forms a thicker adhesive layer and a more flexible interface, which may help to counteract stress resulting from polymerization shrinkage of the resin composite. ${ }^{20}$ Presence of nanoparticle of $\mathrm{SiO}_{2}$ could be the reason for greater shear bond strength of Futurabond DC. Incorporation of nanoparticles improves mechanical properties of dentin bonding agents. ${ }^{21-23}$ The intermediate layer and the resin-impregnated dentin offer an elastic resin-dentin interface to accommodate both the composite and the dentin. ${ }^{24}$ Kim et al. ${ }^{25}$ reported that silica nanofiller containing dentin boinding agent exhibited the highest microtensile bond strength at $1 \mathrm{wt} \%$. They stated that incorporation of nanofillers greater than interfibrillar space $(20 \mathrm{~nm})$ not only increases the viscosity but also causes the agglomeration of filler contents on the dentin surface. Apart from the nanofiller, it is moisture tolerant and also has durable marginal integrity. It has advantages of easy and fast application, i.e., onecoat, one-cure technique. The results of our study showed that there was significant difference in the in vitro dentin shear bond strength of two self-etch adhesives tested. Apart from the nanofiller, it also contains fluorides, which is lacking in seventh-generation bonding agent; thus, it is ideal for pediatric use. ${ }^{13}$ The difference in bond strength may be due to the different compositions and their ratio in the bonding agent which has not been revealed by the manufacturers.

\section{Conclusion}

Shear bond strength of eighth-generation dentin bonding agent, that is, Futurabond DC, was better than seventh-generation dentin bonding agent, that is, Adper Single Bond Universal. And for achieving a definitive conclusion, more in vitro and clinical trials with large sample size and longer follow-ups should be conducted to correlate the factors contributing to their bonding efficacy.

\section{References}

1. McDonald RE, Avery DR. Dentistry for the Child and Adolescent. 6th ed., St Louis: CV Mosby Co; 1994. p. 422.

2. Anusavice KJ. Philips science of dental materials. 11th ed., Saunders Publication; 2003.

3. Buonocore MG. A simple method of increasing the adhesion of acrylic filling materials to enamel surface. J Dent Res 1955;34(6):849-853. DOI: 10.1177/00220345550340060801.

4. Van Meerbeek B, Vargas S, Inoue S, et al. Adhesive and cement to promote preservation dentistry. Oper Dent 2001(Suppl. 6):119-144. 
5. Van Meerbeek B, Yoshihara K, Yoshida Y, et al. State of the art of self-etch adhesives. Dental Mater 2011;27(1):17-28. DOI: 10.1016/ j.dental.2010.10.023.

6. Krithikadatta J, Gopikrishna V, Datta M. CRIS guidelines (checklist for Reporting in-vitro studies): a concept note on the need for standardized for improving quality and transparency in reporting in-vivo studies in experimental dental research. J Conserv Dent 2014;17(4):301-304. DOI: 10.4103/0972-0707.136338.

7. Craig RG. Bonding of dental substrates. Craig Restorative dental materials. 10th ed., Mosby Inc; 2002.

8. Sturdevant's. Art and science of operative dentistry. Fundamental Concept of Enamel and Dentin Adhesion. 6th ed., Elsevier; 2011. 179-202.

9. Hashimoto M, Ohno H, Endo K, et al. The effect of hybrid layer thickness on bond strength: demineralized zone of hybrid layer. Dent Mater 2000;16(6):406-411. DOI: 10.1016/s0109-5641(00)00035-x.

10. Perdigao J, Lopes $M$. The effect of etching time on dentin demineralization. Quintessence Int 2001;32:19-26.

11. Pioch T, Stotz $S$, Buff $E$, et al. Influence of different etching times on hybrid layer formation and tensile bond strength. Am J Dent 1998;11(5):202-206.

12. http://solutions.3mae.ae/wps/portal/3M/en_AE/3M_ESPE/ DentalManufacturers/Products/Dental-Restorative-Materials/ Dental-Bonding/Dental-Adhesive.

13. www.voco.com/in/product/futurabond_dc.

14. Hegde MN, Bhandary S. An evaluation and comparison of shear bond strength of composite resin to dentin, using newer dentin bonding agents. J Conserv Dent 2008;11(2):71-75. DOI: 10.4103/09720707.44054 .

15. Noguchi H, Nakano M, Kumasaka A, et al. Evaluation of Japanese dental nadhesives. Dent Eng 1982;60:16-27.

16. Kerby RE, Knobloch LA, Clelland N, et al. Microtensile bond strengths of one-step and self-etching adhesive systems. Oper Dent 2005;30(2):195-200.
17. Joseph P, Yadav C, Satheesh K, et al. Comparative evaluation of the bonding efficacy of sixth, seventh and eight generation bonding agents: an in vitro study. Int Res J Pharm 2013;4(9):143-147.

18. Kambale $S$, Hedge $V$, Munavalli $A$, et al. Effect of single step adhesives on the marginal permeability of class $V$ resin composites - an in vitro study. J Dent Med Sc 2014;13(5):44-49. DOI: 10.9790/0853-13544449.

19. El Sayed HY, Abdalla Al, Shalby ME, et al. Effect of thermocycling on the micro-shear bond strength of solvent free and solvent containing self-etch adhesives to dentin. Tanta Dental Journal 2015;12(1):28-34. DOI: 10.1016/j.tdj.2014.09.001.

20. Can Say E, Nakajima M, Senawongse $P$, et al. Microtensile bond strength of a filled vs unfilled adhesive to dentin using self-etch and total-etch technique. J Dent 2006;34(4):283-291. DOI: 10.1016/ j.jdent.2005.07.003.

21. Sadat-Shojai $M$, Atai $M$, Nodehi $A$, et al. Hydroxyapatite nanorods as novel fillers for improving the properties of dental adhesives: Synthesis and application. Dent Mater 2010;26(5):471-482. DOI: 10.1016/j.dental.2010.01.005.

22. Solhi L, Atai M, Nodehi A, et al. Poly(acrylic acid) grafted montmorillonite as novel fillers for dental adhesives: synthesis, characterization and properties of the adhesive. Dent Mater 2012;28(4):369-377. DOI: 10.1016/j.dental.2011.11.010.

23. Atai M, Solhi L, Nodehi A, et al. PMMA-grafted nanoclay as novel filler for dental adhesives. Dent Mater 2009;25(3):339-347. DOI: 10.1016/ j.dental.2008.08.005.

24. Wahab FK, Shaini FJ, Morgano SM. The effect of thermocycling on microleakage of several commercially available composite class $\mathrm{V}$ restorations in vitro. J Prosthet Dent 2003;90(2):168-174. DOI: 10.1016/ s0022-3913(03)00300-7.

25. Kim JS, Cho BH, Lee IB, et al. Effect of the hydrophilic nanofiller loading on the mechanical properties and the microtensile bond strength of an ethanol-based one-bottle dentin adhesive. J Biomed Mater Res B Appl Biomater 2005;72(2):284-291. DOI: 10.1002/jbm.b. 30153. 